\title{
Evaluating the Effectiveness of Teachers Training Programs in Islamabad Model Collages
}

\author{
Mohammad Waqas Raja (Corresponding author) \\ Public Affairs School, University of Science and Technology of China \\ 96 Jinzhai Road, Hefei, Anhui, China \\ E-mail: mwaqasraja@hotmail.com \\ Song Wei \\ Public Affairs School, University of Science and Technology of China \\ 96 Jinzhai Road, Hefei, Anhui, China \\ E-mail: songwei@ustc.edu.cn
}

Received: Sep. 17, 2014

doi:10.5296/jse.v4i4.6326
Accepted: Oct. 17, $2014 \quad$ Published: November 1, 2014

URL: http://dx.doi.org/10.5296/jse.v4i4.6326

\begin{abstract}
The present study explored the variables that contribute to the effectiveness of teachers training program in Pakistan for the education sector on the use of information and computer technology trainings. A sample of 111 lecturers from federal government colleges in Islamabad was taken and with the help of a research questionnaire their response was recorded. On its basis the study determined that computer knowledge and skills have been imparted in the trainees but their effectiveness could have been increased if rigorous training need analysis had been done. The study also finds that factors such as support from the head of departments, interest and cooperation from colleagues and availability of physical facilities in the colleges influenced the effectiveness of trainings. The study suggests that foreign training programs are more effective due to presence of experienced trainers and better training facilities. The study also determined that factors like duration of training programs has no effect on effectiveness of training, rather, it requires appropriate time for subject matter to be studied. The study also finds that ICT training programs do not contribute towards career growth and salary increase of teachers and lecturers; rather it affects their level of satisfaction from job. The study suggests that an increase in training budget can make these training programs more effective.
\end{abstract}

Keywords: Teachers, Training, Computer instructions, Performance 


\section{Introduction}

The broad purpose of any training program is to change attitudes, behaviors or skills in a way that positively impacts performance results. Evaluating the effectiveness of a training program in order to understand whether it meets its objectives is critical, as training and development staff is becoming more and more accountable for the effectiveness of their programs. Evaluation can be used to determine whether the training achieves its goals. Evaluation can also assess the value of the trainings, identify improvement areas, and also identify unnecessary training that can be eliminated. Systematic evaluation of training programs is also an important step in improving the overall quality of the training program and measuring its impact on the organization. It is also important to remember that effective evaluation is multifaceted. Most of the literature recognizes the importance of evaluation in terms of client orientation and economic return. In other words, most researchers in the field understand that clients, whether they are those who have hired the trainer or those who have participated in the training, must be satisfied with that training. If clients do not perceive a return on their investment, whether measured in terms of time or financial expense, they may not be willing to continue to invest in the training in future.

\section{Purpose}

The purpose of this paper is to evaluate the effectiveness of education sector training programs. It reviews the potential impact of teacher's trainings in Pakistan focusing on public sector colleges in the federal capital Islamabad. Therefore the principle objectives of this paper were discussed below.

- $\quad$ To propose an effective training methodology for teachers training and describe it in terms of inputs, processes, outputs.

- $\quad$ To specify the internal standards that are required for an effective teachers training program.

- To propose a method or methods for establishing an external criteria that determine whether teachers training is effective or not.

\section{Theoretical Background}

Asian Development Bank (2010) has found that in financial sector firms new projects for effectiveness and impact of training in Indonesia focuses on a model that distinguishes between training inputs, processes, and outcomes and explains that a well structured combination of in country and overseas training produce positive results improving working effectiveness and technical skills and the study find no correlation between technical skills and duration for a training program and finds some short duration training programs to be as effective as long duration programs. Blandly (2009), researchers of Finland University with the assistance of Australian National Training Authority (ANTA) find that Australian insurance firms provide extensive training for their incoming employees. About half the time of incoming employees is taken up with training over the first three months of their employment compared to USA employees who take one third of the time. Dockery (2011) 
reveals little influence of training practices or vocational educational practices on productivity levels in the capital investment firms. Hawker (2009) reviews the experiences revealed by case studies of three firms and shows that enterprise returns to training can be exceptionally high especially for training that is highly specific, rapidly accomplished and related to the introduction of new technology or working patterns. Such training pays a firm even if labor turnover is high. Zemke (2007) a systematic need assessment can guide and serve as the basis for the design, development, delivery and evaluation of the training program. It can be used to specify a number of key features for the implementation and evaluation. Consequently the presence of a comprehensive need assessment should be related to the overall effectiveness of training because it provides a mechanism by which the question central to the successful training program can be answered. Tovey (2008) learner assessments are created to allow a judgment to be made about the learner's capability for performance. There are two parts to this process: the gathering of information or evidence and the judging of the information. This assessment should not be confused with evaluation. Assessment is about the progress and achievements of the individual learners, while evaluation is about the learning program as a whole. Hayes, (2003) consider both hard and soft returns when it comes to customer centric technologies, but give more weight to non financial metrics such as customer satisfaction and loyalty and the performance level informs you of the degree that the learning can actually be applied to the learner's job. It measures how well the performance analysis process worked but he finds it is often difficult to isolate the results of a training program. Kirkpatrick's (1996) four model of training evaluation and criteria continues to be the most popular one can use this frame work to evaluate effectiveness of training programs in terms of Reaction, Learning, Behavior or Results Thus the objective of training determines the most appropriate criteria for accessing the effectiveness of training.

\section{Factors Affecting Training Outcomes}

\subsection{Training Need Analysis}

A training need analysis is a systematic method for determining what causes performance to be less than expected or required. The focus of training is performance improvement, which becomes obvious for doing needs analysis to check that is there a performance discrepancy (actual or expected). And to find the discrepancy a need analysis is required.

\subsection{The Training Methods}

The selection of an appropriate training method to meet the training objectives becomes more and more challenging. The various training methods include lectures, program instruction, virtual reality training, intelligent tutoring system, interactive multimedia training, games and simulations, in-basket technique, case studies etc.

\subsection{The Training Budget}

Many researchers treat training budget as a separate independent variable for evaluating the effectiveness of training program And find that less investment in training have shown poor results but this also depend on the nature of skill and the duration of training program as well. 


\subsection{Training Facility Environment}

Eseryel (2006) training programs in which the environment is friendly are more successful this include the physical resources like seating arrangements, lighting facility, peace and quiet in the training area and even factors outside the training class room like food etc

\subsection{Reinforcement of Training Program}

Bennett \& Huffcutt (2009) have used reinforcement of training program as another variable affecting the outcomes of training programs and the task, skills and techniques learned by the trainees during the training becomes ineffective unless they are reinforced at the workplace by the management of the organization.

\subsection{Supportive Organizational Setting}

Rutherford (2002) organizational setting which include positive attitude towards the knowledge and skills acquired in training by the fellow workers, supervisors and bosses as well as by subordinates is important in applying this knowledge at the actual work place.

\subsection{Trainer Characteristics}

Trainer characteristics play a vital role in the effectiveness of training programs as all the communication and learning by the trainee is through the trainer and he acts as a bridge between the trainee and the training program. These characteristics may include trainer experience in training, his professional knowledge and skills about training program, and the number of persons to be trained.

\subsection{Time Duration}

The duration of training depends upon the tasks and skills to be trained. Researchers like Murphy (2002) \& Huffcutt (2005) ${ }^{1}$ have used it as an independent variable and found that if the task and skills to be trained are complex and require more training sessions the duration of training must be long to make it effective.

\subsection{Trainee Characteristics}

Trainee characteristics play an important role in effecting the outcomes of all training programs. Researchers like Aztec (2004), Clark (1996) have taken it as an independent variable and found various characteristics of trainees like age, qualification, previous training experience, liking about the training program being offered etc.

\section{Effectiveness of Training Programs}

Practitioners have measured the effectiveness of training programs according to the achievement of objectives and goals set by management with the help of training programs. Huffcutt (2005) have taken the effectiveness of a training program as a dependent variable in terms of reduction of expense due to mistakes and more time to complete a task and benefits for trainee career growth. Murphy (2002) calculated the effectiveness of training in terms of 
improving the level of satisfaction and moral and the reduction in turnover as a result of training.

\section{Framework and Methodology}

The present study is on the evaluation of CIT (Computer Instruction Training program) for the teachers of Islamabad model colleges; it identified the factors, which affect the outcomes of teachers training and this is a cross-sectional study and data was be collected only once for the research purpose. The study explains in detail the concepts needed to evaluate of effectiveness of teachers training programs and the data was be collected from the teachers at different colleges who have undergone the training program. Hence the study setting will be non-contrived and the unit of analysis is individual teachers from various model colleges. The study uses convenience sampling method for data collection as information can only be accessed from the trainee only and not from all the teachers at the model colleges and research is based on primary data, collected by the help of a research questionnaire and a total of 111 questionnaires where completed and respondents were grouped into male and female trainees. The sample is large enough to gain insight into the results of trainings. Overall the sample is reasonably balanced in term of gender $56 \%$ of the respondents are female and $44 \%$ are male teachers belonging from different model colleges in Islamabad.

\section{Research Questions}

Following questions were being answered against the objectives set in this paper.

- Does an increasing the budget of training programs can make trainings more effective?

- Does the choice of training method have a significant effect on the training outcomes?

- $\quad$ Does the trainee characteristic have a significant effect on the effectiveness of training program?

- Does trainer's characteristic can significantly affect outcomes of a training program?

- $\quad$ Does the duration of training program affect its outcomes?

- $\quad$ Does the training programs can be made more effective if proper need assessment is done?

- $\quad$ Does the training program can be made more effective if the training provides good training facility?

- $\quad$ Does the training programs can be made more effective if the organizational setting is supportive to the new KSAs learned?

- $\quad$ Does the training programs can be made more effective if it is reinforced by the firm? 


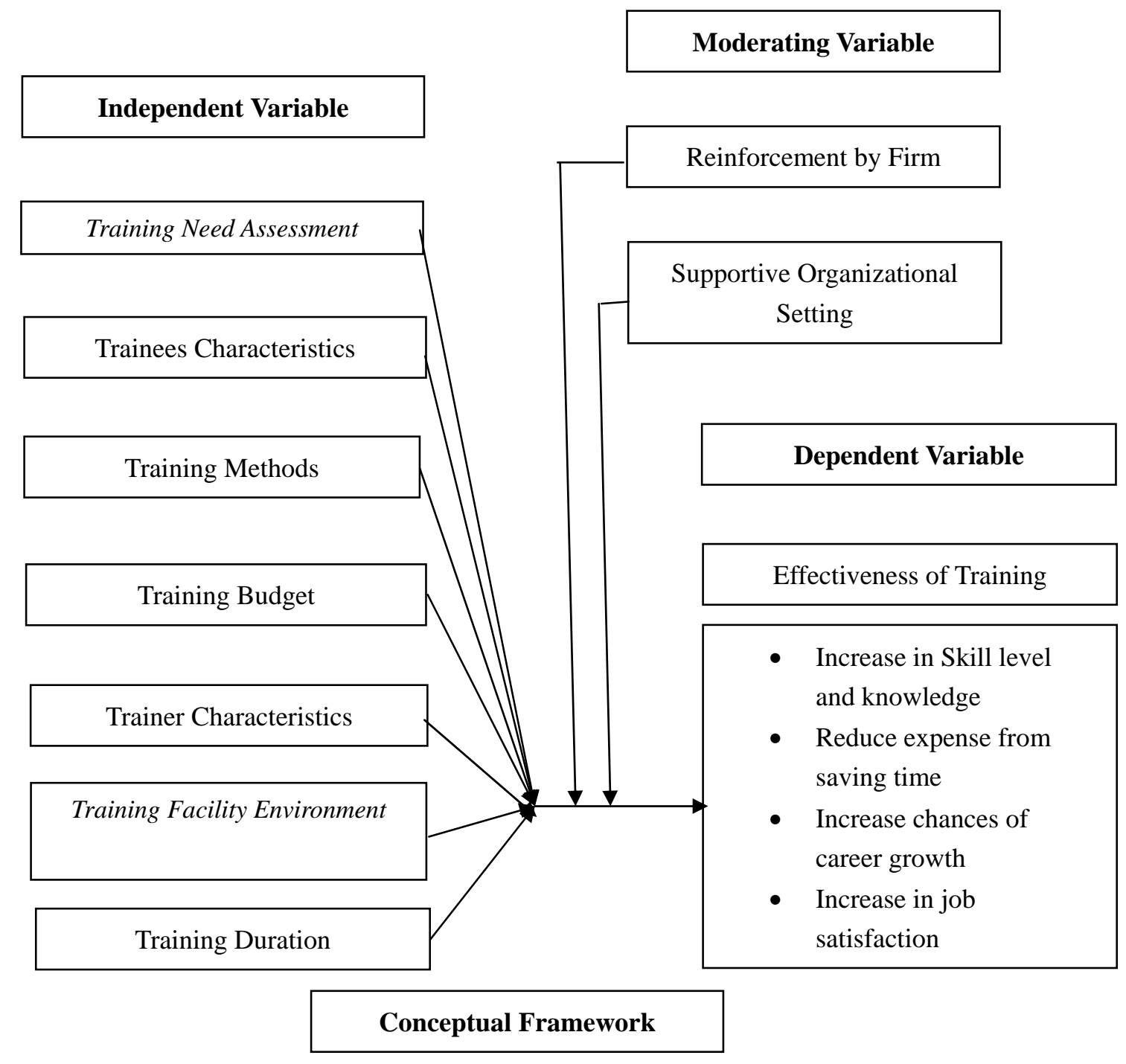

\section{Analysis}

Here we present the analysis for evaluation of the effectiveness of ICT (information and computer training) for teachers of colleges in the federal capital Islamabad. The paper evaluate various factors effecting the outcomes of these training programs and the results have shown that certain variables have strong effect on the varuos training outcomes. It also finds certain other variables having less or moderate effect on the success or faliure of a training program and all these variables will be disscussed here.

To analyze the effectiveness of ICT training programs the study takes a sample of teachers from the training programs conducted from 2012 to 2014. These training programs come under the education sector reforms ESR (2008-2016) plan which is mostly funded by donor agencies like UNESCO, UNDP. ESR program is cast in the long term perspective of national education policy (2006-2020), and the ten year perspective development plan (2005-2015). ESR is a comprehensive sector wide program for increased access, enhanced equity and improved quality at all levels of education. The most important objective is to develop an educated citizenry in which every person has completed at least a minimum level 


\section{Macrothink}

Journal of Studies in Education

ISSN 2162-6952

2014, Vol. 4, No. 4

of education such as universal primary education and the ICT trainings for teachers are one small part of the ESR program.

\subsection{Reliability analysis}

To check the internal consistency of measurement items we have used cronbach alpha value, and its coefficient value should be above .7 in order for the scale to have internal consistency.

Table 1. Reliability analysis for constructs

\begin{tabular}{|c|l|c|c|c|}
\hline S. No & \multicolumn{1}{|c|}{ Construct } & $\begin{array}{c}\text { No of } \\
\text { Items }\end{array}$ & $\begin{array}{c}\text { Cronbach's } \\
\text { Alpha }\end{array}$ & $\begin{array}{c}\text { Average inter } \\
\text { scale correlations }\end{array}$ \\
\hline 1 & Training Need Assessment & 4 & .731 & .500 \\
\hline 2 & Trainees Characteristics & 3 & .714 & .555 \\
\hline 3 & Training Methods & 3 & .700 & .405 \\
\hline 4 & Training Budget & 3 & .705 & .600 \\
\hline 5 & Trainer Characteristics & 3 & .708 & .546 \\
\hline 6 & Training Duration & 3 & .706 & .509 \\
\hline 7 & Training Facility Environment & 3 & .705 & .445 \\
\hline 8 & Reinforcement of Training & 3 & .725 & .622 \\
\hline 9 & Supportive Organizational Setting & 3 & .739 & .577 \\
\hline 10 & Increase in KSA,s & 2 & .780 & .607 \\
\hline 11 & Reduce expense from time saving & 2 & .700 & .541 \\
\hline 12 & Increase chances of career growth & 3 & .724 & .581 \\
\hline 13 & Increase in job satisfaction & 3 & .730 & .435 \\
\hline
\end{tabular}

From table 1 we can see that for almost all constructs the cronbach alpha value lies between .70 to .78 which shows that all items are internally consistent and there average inter scale correlation values are also high ranging from .40 to .60.

\subsection{Student's t-test comparing mean rating to test values of 4.0 and 4.2}

For the purpose of identifying the variables that have a significant effect on the effectiveness of training program, the study uses $t$ test with alpha $=0.05$. The study takes two arbitrary standards at 4.0 and 4.2 which is $75 \%$ and $80 \%$ respectively of the scale on which respondents where asked to rate whether they agree or disagree for the various variables. And the t-test determines which variables are significantly below the arbitrary standard and which are above the arbitrary standard. 
Table 2. Significance of Agreeness Ratings Compared to Test Values of 4.0 and 4.2

\begin{tabular}{|c|l|c|c|l|l|}
\hline S. No & \multicolumn{1}{|c|}{ Items/Variables } & $\begin{array}{c}\text { No of } \\
\text { Response }\end{array}$ & $\begin{array}{c}\text { Mean } \\
\text { Agreeness } \\
\text { Rating }\end{array}$ & $\begin{array}{c}\text { Significance } \\
\text { at test value } \\
\mathbf{4 . 0}\end{array}$ & $\begin{array}{c}\text { Significance } \\
\text { at test value } \\
\mathbf{4 . 2}\end{array}$ \\
\hline 1 & Training Need Assessment & 111 & 3.73 & .951 & $.015^{* *}$ \\
\hline 2 & Training Methods & 111 & 3.56 & .222 & $.003^{* *}$ \\
\hline 3 & Training Facility Environment & 111 & 3.48 & $.004^{* *}$ & $.000^{* *}$ \\
\hline 4 & Trainer Characteristics & 111 & 3.44 & $.023^{* *}$ & $.047^{* *}$ \\
\hline 5 & Trainee Characteristics & 111 & 2.36 & $.005^{* *}$ & $.116^{* *}$ \\
\hline 6 & Training Duration & 111 & 2.86 & $.004^{* *}$ & $.060^{*}$ \\
\hline 7 & Training Budget & 111 & 4.42 & $.015^{*}$ & $.951^{*}$ \\
\hline 8 & Reinforcement of Training & 111 & 2.46 & $.001^{* *}$ & $.007^{* *}$ \\
\hline 9 & Supportive organizational settings & 111 & 4.35 & $.359^{*}$ & $.008^{*}$ \\
\hline 10 & Increase in job satisfaction & 111 & 4.22 & $.009^{*}$ & .119 \\
\hline 11 & Increase in KSA & 111 & 4.05 & $.000^{*}$ & $.132^{* *}$ \\
\hline 12 & Increase chances of career growth & 111 & 2.02 & .335 & $.003^{* *}$ \\
\hline 13 & Reduce expense from time saving & 111 & 3.18 & $.062^{* *}$ & $.001^{* *}$ \\
\hline
\end{tabular}

Students $\mathrm{t}$ - test comparing mean rating to test values of 4.0 and $4.2, \quad \mathrm{p}=0.05$ * Significantly higher than comparison value, ** significantly lower then comparison value, Significance of Agreeness Ratings Compared to test values of 4.0 and 4.2

From table 2 the value for need analysis falls significantly below the comparison value of 4.2 but lies within significance level at comparison value of 4.0 which indicates that $75 \%$ of respondents agree that certain type of need analysis is done before a training programs are offered but less then $80 \%$ believe that need analysis is done. The value for results on training method shows that its value lies in the significance level when we take the test value at 4.0 but at the test value of 4.2 it lies below the significance level which indicates that $75 \%$ respondents or more but less than $80 \%$ agree that training methods used in ICT trainings and other general training programs are effective but at higher level our hypothesis is rejected. The value for results on training facilities at both the test values of 4.0 and 4.2 the value lies below the significance level from this we conclude that less than $75 \%$ respondents agree that the training facility is comfortable and provide good learning environment and there is a need of improvement in the training facilities. The study also finds the values for trainer characteristics, trainee selection criteria, and change in behavior of trainee below the significance level at test values of 4.0 and 4.2, from this it was concluded that less than $75 \%$ respondents finds the trainer to be highly professional, and they do not agree with the selection criteria used, and they do not find a considerable change in behavior as a result of trainings. The value for learning from trainings is higher than the test value at 4.0 but it falls below the test value of 4.2 which suggests that $75 \%$ or more but less than $80 \%$ respondents agree that much learning has take place as a result of trainings. The value for training budget at both the test values at 4.0 and 4.2 is higher then the significance level which suggests that more then $80 \%$ respondents agrees that if the training budget is increased the training programs can be made more effective. The value for the reinforcement of training programs 
falls below the significance level at both the test values of 4.0 and 4.2 which means that less then $75 \%$ respondents agree that training is reinforced after training so there is a need to reinforce training by higher management. The value for change in result is higher then the significance level for both the test values which means that from 75 to $80 \%$ respondents agree that training is useful to them and it will improve the KSA of teachers and lecturers for which it is offered.

\subsection{Ordinary Least Squares Regression Analysis}

For our sample of 111 trained teachers and lecturers the study uses ordinary least square regression to determine the affect of our selected variables on the effectiveness of training programs offered these variables are used as a proxy for the dependent variable and are highlighted in the table.

Table 3. Ordinary Least Squares Regression Analysis

\begin{tabular}{|c|c|c|c|c|c|}
\hline \multicolumn{2}{|l|}{$\mathbf{R}$} & 0.7990 . & & & \\
\hline \multicolumn{2}{|c|}{ R-square } & 0.785 & \multicolumn{2}{|c|}{$\begin{array}{l}\text { Mean Dependent } \\
\text { variable }\end{array}$} & 3.740 \\
\hline \multicolumn{2}{|c|}{ Adjusted R-square } & 0.774 & \multicolumn{2}{|c|}{$\begin{array}{l}\text { Standard Deviation of } \\
\text { D.P }\end{array}$} & 1.013 \\
\hline \multicolumn{2}{|c|}{ F Statistics } & 215 & \multicolumn{2}{|c|}{ Prob (F Statistics) } & 0.000 \\
\hline S. No & Variables & Coefficients & Std. Error & T Statistics & Prob \\
\hline 1 & $\mathrm{C}$ & .298 & .335 & 0.890 & $.003^{*}$ \\
\hline 2 & Need Assessment & .701 & .249 & 2.194 & $.042 *$ \\
\hline 3 & Training Methods & .810 & .110 & 2.034 & $.373^{*}$ \\
\hline 4 & Training Facility & .777 & .164 & 2.263 & $.795 *$ \\
\hline 5 & Trainer Characteristics & .670 & .151 & 0.080 & $.033^{*}$ \\
\hline 6 & Trainee Characteristics & .333 & .039 & 2.964 & .022 \\
\hline 7 & Training Duration & .203 & .178 & 3.510 & .094 \\
\hline 8 & Training Budget & 899 & 993 & 2.007 & $.768 *$ \\
\hline 9 & $\begin{array}{l}\text { Reinforcement of } \\
\text { Training }\end{array}$ & .889 & .679 & 2.160 & $.606^{*}$ \\
\hline 10 & $\begin{array}{l}\text { Supportive organizational } \\
\text { settings }\end{array}$ & .674 & .195 & 2.783 & $.542 *$ \\
\hline
\end{tabular}

* Significant at alpha $=.05$

Dependent Variable $=$ Effectiveness of training Program

The results from the table 3 shows that the value of $\mathrm{R}$ is .799 which means $79.9 \%$ variation in the dependent variable is due to the influence of the independent variables considered in the study and there is a high dependence of dependent variable on the independent variables where as the $\mathrm{R}$ square is $78.5 \%$ and adjusted $\mathrm{R}$ square is $77.9 \%$ and this indicates that nearly 21.1\% variation is caused by other unknown variables that are not considered in the study. The coefficient of $\mathrm{C}$ is .299 and has a significant $\mathrm{P}$ value at alpha $=5 \%$. The coefficient for need assessment is .701 and has a significant $\mathrm{P}$ value of .0424 . The positive relationship 
between need assessment and effectiveness of training programs shows that well planned needs analysis leads to a more effective training program. For training methods the value of coefficient is .810 which shows a strong positive relationship between training methods and effectiveness of training programs it has a significant $P$ value of .0373 at alpha .05 this means that choice of the training methods has a significant effect on the effectiveness of training. The value for trainer characteristics is .670 which shows a positive relationship between the dependent variable and the trainer characteristics this shows that the more experienced and knowledgeable the trainers are the more will be the effectiveness of training. It has a significant $\mathrm{P}$ value of .0802 which confirms our hypothesis. The value of coefficient for trainee selection criteria is .333 which shows a weak positive relationship between effectiveness of training and the trainee selection criteria this means that the result of this study do not find much evidence that the trainee selection criteria has a significant affect on the effectiveness of training and the P value is also not significant at alpha at .05. The study finds a weak relationship between training duration and effectiveness of training program with coefficient value of .203 but the study finds a strong positive relationship for reinforcement of training and training budget with the effectiveness of training program and had coefficient values of .899 and .889 with a significant P values of .768 and .606 at alpha equal to .05 .

\section{Findings}

We come up with some important observations on the basis of the above analysis, which are, if rigorous training need analysis had been conducted before training starts. Such systematic analysis would have provided adequate baseline information that could have enabled decision makers to monitor the effectiveness of teachers training and help them to choose among different training strategies. Factors such as support from supervisors, the interest and cooperation from colleagues and availability of physical facilities influenced the impact of training. This becomes apparent by having more favorable responses of effective training from schools and colleges that have computer labs and other related facilities. To ensure effectiveness and constructive impact. Trainings need to be understood, designed and implemented as part of institutional development program. It is often assumed that such trainings automatically contribute to building institutional capabilities, so any positive change require commitment from principals and head of the departments, so an integrated institutional development strategy is needed to give better results. The results from the research questionnaire shows that both trainings in Pakistan as well as abroad are an effective means to enhance the abilities and computer related knowledge of teachers and lecturers but since training institutions in Pakistan continue to suffer from various problems like shortage of well qualified and experienced trainers and physical facilities etc, so they do not provide a viable alternative to foreign trainings. The study reviewed factors like duration of training programs. The results concluded that effectiveness of trainings is not dependent on the duration of training programs but rather it is dependent on subject matter which is to be studied. The study suggests from the results that trainer communication and professional skills count a lot in the effectiveness of trainings. The study does not find any impact of 
trainings in contributing to the teachers and lectures career growth and salary increases. Rather it effects the satisfaction from their job that they get from the training programs.

\section{Recommendations}

Training programs should be designed in such a way that they are integrated into a broader institutional development program. To maximize the effectiveness and impact of ICT trainings and other general training programs they should not be offered unless the following conditions are met.

1. On the basis of analysis a comprehensive strategy should be developed which considers all the strengths and weaknesses of the schools and colleges and provide a framework for future analysis.

2. The skills and knowledge of trainees (teachers/lecturers) should be determined and assessed before trainings which reflect job requirements and current qualifications. Comparing them with anticipated responsibilities that trainees will be expected to fulfill after the training at the end of the training programs.

3. Supervisors (principals/HOD) must be trained to support trainees after the training programs are completed.

4. A clearly defined mechanism should exist for assisting returned trainees to apply the knowledge and skills that they are trained for which include supervisors support and guidance etc.

5. Information on best training institutes must be collected to assist the training managers at FDE (Federal Directorate of Education) to make good decisions in identifying these institutes.

\section{References}

Ann P. B. (2007). Measuring the Employees Returns on Investment in Training. American Business Post, 9, 23-29.

Aztec, Martin. (2004). The Death of ROI and the Rise of a New Management Paradigm. The Business Series, 2(3), 33-56.

Bassi, L. J., \& Van, M. E. (2009). ASTD State of the Industry Report, Alexandria, VA. The American Society for Training and Development, 7(2), 341.

Blandly, K.(2009). Effectiveness of Training in Organizations. Journal of Applied Psychology, 12(2), 234-245.

Clark. (1996). Training for Information Technology. Journal of Technology Standards, 11, 34-38.

Dockery, M., \& Anne, H. (2011). Does Training Pay, Australian National Training Authority, ISBN, 17-69. 


\section{Macrothink}

Journal of Studies in Education

ISSN 2162-6952

2014, Vol. 4, No. 4

Eseryel, D., \& Spector, J. M. (2006). Current Practice in Designing Training for Complex Skills. Association for Advancement of Computing in Education, Austria, 71-89.

Hawker, H .f. (2009). Training Needs Analysis and Evaluation. Institute of Personnel and Development, 6, 67-69.

Hayes, S.L. (2003). Evaluating sales Training Program, Multi Channel Service White Paper, Siebel System Inc, Australia, 4-17.

Huffcutt, P. R. (2009). How to Develop and Present Staff Training Courses. Kogan, 7, 36-37.

Kirkpatrick, D. L. (1996). Evaluation of Training', in Training and Development Handbook. McGraw-Hill, p .451-521.

Murphy, D. (2002). Evaluating Cost Effectiveness of Online and Face to Face Instruction. Educational Technology and Society, 7, 167-175.

Murphy, D., \& Huffcutt P. R. (2005). Impact of Labor Market Reform on Effectiveness of Training Program in Germany. The Labor Economics, 14, 19-27.

Rutherfod, P. B., Bird, M., \& Rackham, N. (2002). The Evaluation of Management Training. Gower, 6(2), 450-451.

Tovey, T. C. (2008). Statistical Methods for Measuring Training Results in Training and Development Handbook, McGraw-Hill, USA, Chapter 9, p. 321.

WTOL. (2000). A Glossary of UK Training and Occupational Learning Terms, $5^{\text {th }}$ edition, J. Brooks, ITOL, Chapter 3, p. 67.

Zemke, L. J. (2007). Principles of Instructional Design. Rinehart \& Winston, 19, 56-58. 